\title{
Methane isotopologues in a high- concentration gas hydrate reservoir in the northern Gulf of Mexico
}

StePHEN C. PhILlips ${ }^{1 *}$, Michael J. Formolo ${ }^{2}$, DAVID T. WANG ${ }^{2}, \mathrm{HAO} \mathrm{XIE}^{3}$, STEPHEN P. BECKER ${ }^{2}$, AND JOHN

\author{
M. EILER ${ }^{3}$
}

${ }^{1}$ Institute for Geophysics, Jackson School of Geosciences, University of Texas at Austin, Austin, TX, USA 78758

(*correspondence: phillips.stephen.c@gmail.com)

${ }^{2}$ ExxonMobil Upstream Integrated Solutions Company, Spring, TX, USA 77389

${ }^{3}$ Division of Geological and Planetary Sciences, California Institute of Technology, Pasadena, CA, USA 91125

We analyzed the multiply-substituted (aka "clumped") isotopic signature of methane in hydrate from a sandy silt reservoir in the northern Gulf of Mexico (Green Canyon 955). The gas was collected by depressurizing a pressure core from 418 meters below seafloor in which $83 \%$ of the pore space was filled with methane hydrate $\left(99.99 \% \mathrm{CH}_{4}\right)$ [1]. Due to the large volume of gas produced $(23 \mathrm{~L})$ and the stepwise degassing method, we collected 4 gas samples over the course of depressurization. $\Delta{ }^{13} \mathrm{CH}_{3} \mathrm{D}$ ranges between 4.84 and 5.85 $\%$, corresponding to apparent isotopic temperatures between 23 and $58{ }^{\circ} \mathrm{C} . \Delta^{12} \mathrm{CH}_{2} \mathrm{D}_{2}$ ranges between 9.65 and $14.71 \%$, corresponding to apparent isotopic temperatures between 64 and $123{ }^{\circ} \mathrm{C}$. Both $\Delta{ }^{13} \mathrm{CH}_{3} \mathrm{D}$ and $\Delta{ }^{12} \mathrm{CH}_{2} \mathrm{D}_{2}$ increase, while apparent isotopic temperature decreases, with cumulative hydrate dissociation within the core sample. Our results suggest that clumped isotopes of methane in hydrates can yield reasonable temperature estimates, but that the role of fractionation during hydrate formation and dissociation needs to be further explored. The fractionation in clumped isotopes during hydrate dissociation suggests the possibility of a signal that could be used to fingerprint methane in the ocean or atmosphere that was formerly contained in hydrate.

[1] Phillips et al. (2020) AAPG Bulletin, doi:10.1306/01062018280 